$\left.\begin{array}{l}\text { Sournals } \\ \text { ONTERNATIONAL JOURNAL OF } \\ \text { ORGANIZATIONAL LEADERSHIP }\end{array}\right) \begin{gathered}\text { INDUSTRIAL } \\ \text { MANAGEMENT } \\ \text { INSTITUTE }\end{gathered}$

\title{
The rate of the productivity of human resources, capital, and energy in sub- sectors of industry during 1991-2011
}

\author{
Morteza Parandakh, Masoumeh Kiani* \\ Master of Development and Economic Planning
}

\begin{abstract}
Keywords:

Productivity of Human

Resources, TFP,

Econometric Method, ARDL

Correspondence:

masoomeh.kiany64@yahoo. com

This study estimated the rate of productivity of human resources, capital, and energy (electricity) in a selection of sub-sectors of industry (basic metals, chemicals, non-metallic minerals, rubber and plastic products, and food products) during 1991-2011 using the econometric methods. For this purpose, first, the amount of the stability of the model's variables in time series was tested. Then, the existence of co-integration between them was determined and, finally, the productivity of the model was calculated using ARDL. According to the results, the elasticity of labor force, capital and energy were 1.07, 1.47 and 0.23 , respectively.
\end{abstract}

(C)AIMI Journals

Nowadays, due to the limitations of various factors of production, our world needs greater productivity in the production of goods and service. Therefore, productivity has an effective and important role in developing production and increasing competitiveness. By its promotion, high-quality and cheap products can be produced and it can provide the required grounds to enter into global markets. Thus, not only all of the country's production potential will be used, but also it is possible to develop this potentiality. Therefore, having information about productivity and production levels as well as recognizing the factors influential in production is crucial for planners and managers. Experts in different economic systems have always emphasized on increasing these kinds of information. Since the adjustment policies of 
human resources have an important impact on the productivity of labor force and also on increasing educated people, therefore, the recognition of the important factors influencing the productivity and the role of these factors in the efficiency of the company is of primary importance for managers. Trying to understand the exact implications of productivity and determining the effective factors which increases it, is one of the necessary requirements for economic development and social welfare. By promoting productivity, it is possible to produce products with superior quality and lower price which provides grounds for entering into the global markets. Thereby, not only all existing production potentiality of the country will be employed, but also it will provide the conditions for developing these potentialities (Emami Meybodi, 2000).

Officially and for the first time, Quesnay employed the word 'productivity' in 1776 in his article. More than a century later, in 1883, Littre defined productivity as the 'ability to produce' and also claimed that, in fact, the desire to produce can be considered as productivity; for the first time, he mentioned the relationship between output and data in his definition. Since the early twentieth century, the word had a more precise meaning. By 1900, Early defined it as the relationship between output and the equipment used for producing output (Abtahi \& Kazemi, 1996).

Economists consider productivity as the ratio of outputs to relevant inputs and they use different methods such as production function, index methods, and input-output method to estimate it. Productivity index model include Kendrick-Creamer, Craig-Harris, Hines, American Productivity Centre and Sumanth (Motmeni, 2008) and their application is dependent on usage and the user (Baharestan, 2007). In production function method, after estimating production function, elastic factors of production is calculated and then they are employed in the calculation of productivity. Over the last half century, economists have widely used this method and this is the basis of many other methods. The production functions models consist of Cobb-Douglas, constant elasticity of substitution, transcendental, Spelman, Leontief, and translog. All of these functions are based on experimental observations starting with the initial default of environmental elements (Azarbayjani, 2009; Motmeni, 2008).

Input-output table is one of the foundations of economic analysis and also one of the tools used in economic planning; one of the tables derived from this table is called the inverse Leontief. This technique has been used at the national level and industry and underused in institutions (Baharestan, 2007). 
Input-output model is used to calculate the marginal TFP and the output changes are divided into production factors; but the calculation of labor productivity and judging it, just by using the ratio of output to data, gives misleading results. Employing the ratio of output to labor to determine labor productivity in the different industrial sector may be higher for some and lower for others and this only can confirm labor productivity if the amount of capital being considered identical for all sectors but actually there is not such a thing (Molaei, 2005). To solve the problem, the complementary indices are used. Thus, the labor productivity index is integrated with other indices such as the index of TFP (user parameters) to understand more accurately why and how the changes in the industrial sectors occurs (Akbari, 2010).

\section{The Literature Review}

The importance and the role of productivity growth and optimal use of resources was an intrigue to conduct some extensive studies to determine the level and its contributions in different grounds. Aghighi (2009) in a study evaluated the impact of partial indicators of performance on total factor productivity (TFP) in Iranian Offshore Oil Company (IOOC) in 1997-2006 by econometric and statistical models. The main method used in this study was Solow growth model with a Cobb-Douglas production function. The relevant organizations such as the Asian Productivity Organization and the National Productivity Organization of Iran approved using this method. Furthermore, Kendrick model was used to compare the results of the main methods and increase the reliability and accuracy of the results. In either case, almost the same results were obtained. The results indicated that in the company under study, the most effective part of the partial indicators of performance was the ratio of staff and queue which reflected the importance of organizing and presented the company's appropriate organizational chart. Then, indicators of expertise, the technology used in the operation of wells, and the amount of training of human resources had the greatest impact.

Rezaei (2009) evaluated the changes in TFP in Tehran Stock Exchange using linear programming method which is a non-parametric method. First, the technical performance of Tehran Stock Exchange was evaluated and then employing Törnqvist index, the growth of productivity of production factors since 1980 to 2006 was assessed. The results showed that the average annual growth of TFP in the Tehran Stock Exchange is equivalent to $0.902 \%$ which is too far from the objectives contained in Iran's fourth plan. 
Broersma and Van Ark (2007) aimed at the distribution of knowledge intensive business services (KIBS) in connection with information and communication technology-based innovations and their impact on productivity growth. They found a significant positive relation between KIBS diffusion and the intensity of information technology (IT) and both IT and KIBS contributed positively to labor productivity growth.

Tanuwidjaja and Thangavelu (2007) analyzed the relationship between structural changes and productivity performances of the manufacturing sector in the Japanese economy. The analysis was done by classifying the manufacturing industries into four sectors, namely lowtechnology, medium-low-technology, medium-high-technology, and high technology. They found that the higher productivity performance in the Japanese economy occurred most remarkably in the medium-high-technology sector. This shifted Japan's comparative advantage from lower technology to higher technology manufacturing.

In a study, Wu (2008) found that growth in China has largely been driven by factor inputs. Total factor productivity growth tends to play a positive role in economic growth during 1993-2004. While technological progress seems to be comparatively permanent over time, scale efficiency has presented scarcely any contribution to China's growth during that period.

Minondo (2010) showed that if products are distinguished by quality level, there is no longer a vigorous relationship between specializing in products associated with higher productivity levels and faster growth. On the contrary, specialization in products allowed a larger opportunity for quality improvement that resulted in higher economic growth.

In an investigation, Abdel-Wahab and Vogl (2011) examined the trend of productivity growth across Europe, the US, and Japan. The main focus was on comparing the productivity performance of the construction sector to that of other industries. A growth accounting framework was implemented to evaluate the contribution of capital, labor quality and total factor productivity (TFP) to productivity growth during 1971-2005. It was discovered that there exist a general reduction in labor productivity growth in total industries inclusive of construction across major OECD countries except UK. With the exception of the UK, TFP negatively impacted labor productivity growth in the period 1990-2005.

Kathuria, Raj, and Sen (2013) addressed the role of institutional quality as captured by effective state-business relationships (SBRs) in influencing sectoral productivity. The study employed a Cobb-Douglas production function to estimate TFPG for nearly 90 industries. The outcomes showed that SBR had positively influenced the TFPG of Indian industry. The outcome, however, was basically for the formal sector. 
Deb and Ray (2014) evaluated the impact of economic reforms of 1991 on productivity change in Indian manufacturing at a disaggregated level of industrial grouping. The results revealed that at the all-India level, only in cotton textile and chemical and chemical products, industries' productivity growth slowed down considerably after the reforms. While productivity in other industries developed after the reforms, there existed sign of interindustry variation in productivity growth rates. In another study, Deb (2014) made an effort to recognize the channels through which economic reforms improved the productivity growth in total manufacturing sector in India. The results revealed that the annual average capacity utilization rate in Indian manufacturing was lower over the post-reform years. To this end, after the reforms, the capacity utilization rate grew faster. Subsequent regression analysis asserted that economic reforms influenced productivity growth in total manufacturing beyond the positive impact of improved capacity utilization.

Farhadi, Islam, and Moslehi (2015) suggested that the negative growth effects of resource rents might turn positive in countries with significant economic freedom. Zhang and Ye (2015) evaluated energy and environmental technical efficiency in China employing a flexible parametric hyperbolic distance function framework and then separated the development of environmental total factor productivity into two component measures, namely environmental efficiency change and environmental technical change based on the calculated hyperbolic distance functions. They discovered that there existed a significant distribution in environmental efficiencies across provinces and regions and the growth of environmental productivity was relative because of the environmental technical change rather than the environmental efficiency change.

Oh (2015) examined TFP growth, technical change, and economies of scale measure of Korean fossil-fuel power generation companies (GENCOs) between 2001 and 2012. He examined the cost function along with specification tests to discover the most relevant empirical model. Empirical results revealed TFP deterioration, technical regress, and economies of scale for the study period. The ideal size of the Korean GENCOs was also discovered that is used in expanding policies concerning TFP growth and technical advance. Slavtcheva (2015) in his study demonstrated that the positive influence of fixed exchange rate regime on growth was greater for countries with lower levels of financial development because inflation and the fraction of deposits held as reserves were typically higher in these countries. 


\section{Method}

In the current study, the data were derived from ten workers employed in Iran's industrial workshops published annually by Statistical Center of Iran and Management Organization. The use of heterogeneous raw data on labor force according to econometric methods would deviate the research results; therefore, all labor forces and employment in these industries were homogeneous.

The variables used in this study were extracted from Central Bank of the Islamic Republic of Iran and the Iranian Statistical Center during 1991-2011. They included data in a selection of sub-sectors of industry (basic metals, chemicals, non-metallic minerals, rubber and plastic products and food product). In general, the sum of all data including the number of workers, value added, capital and energy, and other data mentioned in the following:

The number of employees (L), the amount of output (Y), Capital stock (K) and the amount of energy $(E)$

Due to the existence of the model's non-static variables and also because we did not want to confront false regression, the Autoregressive Distributed Lag (ARDL) was used without taking into account the unreliability of the parameters. But the proper interval for the variables was determined to estimate the appropriate templates.

Accordingly, at first, model was estimated regarding all possible combinations using the ordinary least squares (OLS) based on different intervals and then the long-term equilibrium relationship between the variables of the model was tested. To find a long-term relationship, the sum of the coefficients of the dependent variables should be less than 1 . The following hypothesis tests this relationship:

$$
\left\{\begin{array}{l}
H_{0}: \sum_{i=1}^{m} \hat{\alpha}_{i}-1 \geq 0 \\
H_{1}: \sum_{i=1}^{m} \hat{\alpha}_{i}-1<0
\end{array}\right.
$$

T-statistic quantity required for the test was calculated as follows:

$$
t=\frac{\sum_{i=1}^{m} \hat{\alpha}_{i}-1}{\sum_{i=1}^{m} \hat{s}_{i}}
$$

If the $\mathrm{t}$-statistic is greater than the critical value, hypothesis $\mathrm{H}_{0}$ is rejected and this means that in the long run, equilibrium relationship exists. 


\section{Error Correction Model}

Despite having a long-term relationship, it may not be possible to balance them in short term; therefore, the model should be estimated in such a way that the value of short-term fluctuations should be associated with the value of their long-term. For this purpose we used the ECM model. ECM models is generally shown as follows:

$$
\Delta y_{t}=\lambda_{0}+\alpha_{0} \Delta x_{1 t}+\alpha_{1} \Delta x_{1 t-1}+\alpha_{2} \Delta x_{1 t-2}+\ldots+\beta_{1} \Delta y_{t-1}+\beta_{2} \Delta y_{t-2}+\ldots+\delta E C M_{t-1}
$$

Where $\delta$ represents the deviation adjustment and imbalance from one period to the next. Whatever the value of $\delta$ greater, the speed of adjustment would be higher.

\section{Estimates of Capital Stock}

In exponential methods, the capital stock is estimated by the following equation:

$\mathrm{I}_{i t}^{n}=\mathrm{I}_{0}^{n} \cdot e^{\sigma t}$

Its logarithmic form is as follows:

$\operatorname{LnI}_{t}^{n}=\operatorname{LnI} I_{0}^{n}+\sigma \tau$

After estimating above equation by OLS, the results are as follows:

$\operatorname{LnI} I_{t}^{n}=13 / 30+0 / 17 \mathrm{~T}+2 / 01 \mathrm{AR}(1)=13.77$

$\mathrm{t} \quad(28 / 66) \quad(18 / 26)$

$\mathrm{R}^{2}=0 / 93 \quad \mathrm{D}-\mathrm{W}=1 / 86$

$\mathrm{I}^{\mathrm{n}}{ }_{\mathrm{o}}=\exp 13 / 77=4955509 / 51$

$K_{0}=\frac{\mathrm{I}_{0}^{n}}{\sigma}$

$K_{0}=\frac{4955509 / 51}{0 / 05}=47775 / 9$

And, Capital stock values in different years are calculated as follows:

The amount of energy (E)

Hence, the model used in this study is defined as:

$\mathrm{Y}=\mathrm{F}(\mathrm{L}, \mathrm{K}, \mathrm{E})$

\section{Results}

The Results of Dynamic Estimation (Short-Term) 
At this stage, after ensuring the long-term relationship, by the use of ARDL dynamic model and the intervals determined by Bayesian-Schwarz information criterion, the results of the model's short-term estimation were obtained and it is shown in Table 1.

Table 1

Short-term Results of Total Productivity by ARDL

\begin{tabular}{cccc}
\hline Variable & Coefficient & T-statistics & Prob \\
\hline$Y_{(-1)}$ & -0.55 & -3.82 & .0112 \\
$Y_{(-2)}$ & -1.135 & -9.89 & .000 \\
$L$ & 0.9629 & 5.5 & 0.003 \\
$L_{(-1)}$ & 0.3533 & 1.47 & 0.21 \\
$L_{(-2)}$ & 1.56 & 8.8 & 0.00 \\
$K$ & 3.8 & 3.08 & 0.012 \\
$K_{(-1)}$ & 9.33 & 6.81 & 0.001 \\
$K_{(-2)}$ & -9.26 & -10.29 & 0.000 \\
$E$ & -0.33 & -12.29 & 0.00 \\
$E(-1)$ & -0.15 & -7.31 & 0.00 \\
$E(-2)$ & -0.129 & -9.45 & 0.00 \\
$C$ & -3.39 & -6.06 & .002 \\
\hline
\end{tabular}

$R^{2}=0.99 \quad F=1076 / 8 \quad D W=2.08$

A:Serial correlation $\quad F=3.44(0.137)$

B: Functional form $\quad F=10.62(0.272)$

C: Normality $\quad F=0.132(0.93)$

D: Hetroscedasticity $\quad F=0.051(0.823)$

Source: research findings

As Table 1 represents, the sign of estimated coefficients were consistent with the theoretical foundations and all of them were statistically significant at the $90 \%$ confidence level. The coefficient of determination which was $99 \%$ indicated that the explanatory power of the model was high, as well as diagnostic tests confirmed the establishment of all the classic assumptions for the given model (no autocorrelation, correct consequential form, normality of residual sentences, and homogeneity of variance).

According to the results of the equation (4-5), the lack of co-integration between the templates' variables could be evaluated. T-value for this test was calculated as follows:

$$
t=\frac{\sum_{i=1}^{p} \hat{\alpha}_{i}-1}{\sum_{i=1}^{p} S \hat{\alpha}_{i}}=\frac{(-0 / 55218-1.1356)-1}{(0.14462+0.11475)}=-6 / 10
$$

Table 2 shows the critical values by Banerjee, Dolado and Mestre (1998). 
Table 2

The Critical Values by Banerjee, Dolado and Mestre (1998)

\begin{tabular}{cccc}
\hline & $\boldsymbol{T}$ & $\mathbf{0 . 0 5}$ & $\mathbf{0 . 1 0}$ \\
\hline$K=2$ & 25 & $-3 / 64$ & -3.24 \\
& 50 & -3.56 & -3.20 \\
\hline
\end{tabular}

Computational statistics was 10.6 and since the absolute value of this statistic was more than critical value (56.3) obtained by Banerjee, Dolado and Mestre, therefore, the null hypothesis i.e., the lack of co-integration between templates variables was rejected and the existence of a long-term equilibrium relation between the variables of the templates was confirmed.

\section{The Results of Long-Term Model}

After estimating the dynamic model (short-term), and confirming the existence of long-term relationship, the amount of this relationship was estimated and the results of the estimates are shown in Table 2. Because the model was logarithmic, coefficients of the independent variables represented the elasticity of the dependent variable. According to the results, all explanatory variables were statistically significant; the elasticity of labor was equal to 1.07 which reflected the production factor as well as positive and increasing impact of labor force on production. This means that $1 \%$ increase in the labor force would increase the production by $1 / 07 \%$ and $1 \%$ increase in investment would lead to a $1.4 \%$ increase in production. However, it is not the same for energy; in fact, the results of long-term estimates showed that $1 \%$ increases in energy consumption decrease the production as much as $26 / 1 \%$ which is associated with much lower energy prices in Iran.

Table 3

The Results of the Estimation of Long-Term Model

\begin{tabular}{cccc} 
Tariable & Coefficient & t-statistics & prob \\
\hline$L L$ & 1.07 & 9.7 & $0 / 000$ \\
$L K$ & 1.4 & 32.7 & $0 / 000$ \\
$L E$ & -0.23 & -12.6 & $0 / 000$ \\
$C$ & -1.26 & -4.096 & $0 / 004$
\end{tabular}

\section{The Result of Estimating Error Correction Model (ECM)}

The recursive method with distributed lag is used to assess short-term deviations of variables from their equilibrium values. Error correction model (ECM) is also used to adjust and 
estimate the long-term relationship. The most important thing in error correction model is the coefficient of error correction model (ECM) which is indicative of the speed of the adjustment for the imbalanced process. This factor is significant and reflects a negative point and confirms co-integration between variables. According to theoretical expectations, if you move from one period to the next period, up to $26 \%$ of the variation is balanced in the labor force's productivity function in its long-term path by templates variables in the next period.

\section{Calculation of the Total Productivity}

Broadly speaking, productivity indices are divided into the index of total factor productivity (TFP) and partial productivity index (LPI). In LPI, an input-output relationship is concerned; while in indices of TFP, output associated with the inputs are evaluated. TFP Index (both labor force and capital) is the ratio of the output to data and in fact represents the average production per unit of production resources.

To measure TFP, Dyvyzhya index are used. In this index, by assigning different weights to the factors of production, the role of each of these factors in the production process is identified. This index allows heterogeneous factors for labor force and capital to be considered the same. In this method, total factor productivity is defined as:

$T F P=\frac{V_{t}}{K_{t}^{\alpha} \cdot L_{t}^{\beta} \cdot E_{t}^{\gamma}}$

Where $\mathrm{V}$ represents GDP, $\alpha$ and $\beta$, and $\gamma$ indicate the contribution of energy (E), capital $(\mathrm{K})$, and labor force, respectively.

It is worth noting that the results of estimated TFP obtained from this model using Solow residual method is identical.

The below relationship, which is the Solow residual, was obtained:

$\widehat{T} \hat{F} \hat{P}=\widehat{V}-\alpha \widehat{L}-\beta \widehat{K}-\gamma \widehat{E}$

The study aimed to estimate the production function and the elasticity of capital and labor force by estimating a Cobb-Douglas production function. This function is as follows: If the above equation is written as:

$\mathrm{Y}=\mathrm{A} L_{1}^{\alpha} K_{2}^{\beta} E_{3}^{\gamma}$

We realize that how much is the productivity of other factors (all factors except labor, capital, and energy) and this is the same amount of A in Cobb-Daglas which is referred as technology coefficient. It is estimated in logarithmic form as follows: 
$\operatorname{Lny}=\operatorname{Ln} A+\alpha \operatorname{LnL}+\beta \operatorname{LnK}+\gamma \operatorname{LnE}$

Estimating TFP using the function of production as well as estimating it by ARDL during 1991-2011 is as follows: Appendix (15)

$\operatorname{LnY}_{t}=-1.216+1.0712 \operatorname{LnL}+1.4755 \operatorname{LnK}-0.2315 \operatorname{LnE}$

$\mathrm{t} ; \quad(-4.96)$

Where $\mathrm{Ln}$ is natural logarithm, $\mathrm{L}$ is the number of employees, $\mathrm{K}$ is the capital, $\mathrm{E}$ is the energy, and $\mathrm{Y}$ is the value of output. Intercept anti-log model suggests TFP. For example, TFP in 1991 is calculated as follows:

$$
\begin{aligned}
& \operatorname{Ln} Y_{70}=-1.216+1.0712(5.08)+1.4755(5.97)-0.2315(4.93)=11.8578 \\
& \text { TFP70 }=\exp (11.8578)=141184.54
\end{aligned}
$$

which shows that TFP in 1991 is equal to 141,184 thousand riyals.

\section{Conclusion and Recommendations}

The current time period may in a sense be a crucial period for the industry, a period during which significant changes occurred in the industry in terms of software (determining the framework, projects and programs, rules and regulations, etc.) and also in terms of hardware (development agencies, financial and credit institutions and building factories in various sectors) and while improving its position compared with other sectors of the industry, specified its directions for next years and even next decades. It had a lasting impact on this ground as well as on the whole of economic structure.

Therefore, the evaluation and analysis of efficiency and productivity in the manufacturing sector during the passage of time can give insights to decision-makers in this sector as well as to Iran's economic system and pave the way forward in the future. Therefore, in this analysis the efficiency and productivity of selected sub-sectors of the industry have been calculated.

The results obtained from the short and long-term model showed that the elasticity of the rate of labor productivity in industry (5 sub-sectors) and also the elasticity of the capital is positive and statistically significant. One percent increase for each wouldl increase the amount of production by $07 / 1 \%$ and $4 / 1 \%$, respectively. However, the elasticity of the rate of energy efficiency (EE) in industry (5 sub-sectors) is negative and statistically significant, that is $1 \%$ increase in energy would reduce total production by $-0.23 \%$. Therefore, it is of prime importance to promote more efficient use of labor and capital. The results of the calculation of the rise of total factor productivity and increased production during the studied period 
confirms that. Furthermore, the results of the calculated TPF during 1991-2011 reflect an increase in productivity.

On the other hand, in the Cobb-Douglas function, increasing or decreasing returns to scale can be obtained by the elasticity of total factor. In other words, the calculations of this study showed that returns to the scale was positive and equal to 24.2 which suggested the existence of increasing returns in this model. Subsequently, it showed that the development and growth of studied industries was due to economies of scale and by increasing inputs of capital primarily and human resources secondarily, we can make some attempts to develop the industry.

\section{References}

Abdel-Wahab, M., \& Vogl, B. (2011). Trends of productivity growth in the construction industry across Europe, US and Japan. Construction Management \& Economics, 29(6), 635-644.

Abtahi, H., \& Kazemi, B. (1996). Productivity. Tehran: Institute for Trade Studies and Research.

Aghighi, M. (2009). Evaluation of the impact of minor performance indicators on total-factor productivity (TFP) in Iranian Offshore Oil Company (IOOC) in the years 1997 to 2006 by econometric and statistical models. Iran's Economic Research, 40, 180.

Akbari, N. (2010). Analysis of the impact of Islam on the formation of social capital. Journal of Economic Research, 5, 1345.

Azarbayjani, K. (2009). Measuring productivity in the industries of Iran (Unpublished master's thesis). Faculty of Economics, University of Isfahan, Isfahan.

Baharestan, A. (2007). Measurement and analysis of factor productivity in wheat production, during the First Development Plan (1988-1993). Journal of Program \& Budget, 19, 53-74.

Banerjee, A., Dolado, J., \& Mestre, R. (1998). Error-correction mechanism tests for cointegration in a single-equation framework. Journal of Time Series Analysis, 19, 267-283.

Broersma, L., \& Van Ark, B. (2007). ICT, business services and labor productivity growth. Economics of Innovation \& New Technology, 16, 433-449.

Deb, A. K. (2014). Economic reforms, capacity utilization and productivity growth in Indian manufacturing. Global Business Review, 15, 719-746.

Deb, A. K. \& Ray, S. C. (2014). An inter-state analysis of total factor productivity growth in selected two-digit manufacturing industries in India. Global Business Review, 15, 59-86.

Emami Meybodi, A. (2000). The principal of efficiency and productivity analysis. Tehran: Institute of Studies and Trade Researches.

Farhadi, M., Islam, Md. R. \& Moslehi, S. (2015). Economic freedom and productivity growth in resource-rich economies. World Development, 72, 109-126.

Kathuria, V., Raj, S. N., \& Sen, K. (2013). Institution of state-business relation and its impact on manufacturing productivity growth in India: A post-reform analysis. South Asia Economic Journal, 14(1), 83-108.

Minondo, A. (2010). Exports' quality-adjusted productivity and economic growth. The Journal of International Trade \& Economic Development, 19(2), 257-287.

Molaei, M. (2005). Evaluating and comparing the productivity of small and large industrial groups in Iran. Journal of Economic Research of Iran, 22, 157-176.

Motmeni, A. (2008). The estimation of contribution of human capital in economic growth during 1966-2001. Iran's Economic Research, 17, 79-98.

Oh, D-h (2015). Productivity growth, technical change and economies of scale of Korean fossil-fuel generation companies, 2001-2012: A dual approach. Energy Economics, 49, 113-121. 
Rezaei, J. (2009). Assessment of the changes in total productivity factors in Tehran Stock Exchange employing Törnqvist index. Journal of Economic Research, 2, 103-122.

Slavtcheva, D. (2015). Financial development, exchange rate regimes and productivity growth: Theory and evidence. Journal of Macroeconomics, 44, 109-123.

Tanuwidjaja, E. \& Thangavelu, S. (2007). Structural change and productivity growth in the Japanese manufacturing industry. Global Economic Review, 36(4), 385-405.

Zhang, Z. \&Ye, J. (2015). Decomposition of environmental total factor productivity growth using hyperbolic distance functions: A panel data analysis for China. Energy Economics, 47, 87-97.

$\mathrm{Wu}$, Y. (2008). The role of productivity in China's growth: New estimates. Journal of Chinese Economic \& Business Studies, 6(2), 141-156. 